\title{
RISK MANAGEMENT PRACTICE IN CHINA'S PUBLIC-PRIVATE PARTNERSHIP PROJECTS
}

\author{
Yongjian Ke ${ }^{1}$, ShouQing Wang ${ }^{2}$, Albert P. C. Chan ${ }^{3}$ \\ ${ }^{1}$ Department of Construction Management, Tsinghua University, Beijing 100084, China; \\ Department of Building, National University of Singapore, 4 Architecture Drive, Singapore 117566 \\ ${ }^{2}$ Department of Construction Management, Tsinghua University, Beijing 100084, China \\ ${ }^{3}$ Department of Building and Real Estate, The Hong Kong Polytechnic University, Hung Hom, Kowloon, \\ Hong Kong Special Administrative Region, China \\ E-mails: ${ }^{1} b d g k y @ n u s . e d u . s g$ (corresponding author); ${ }^{2}$ sqwang@tsinghua.edu.cn; ${ }^{3}$ bsachan@polyu.edu.hk
}

Received 18 Aug. 2010; accepted 30 May 2011

\begin{abstract}
Project risks were not properly managed in the many past Public-Private Partnership (PPP) projects in China. Although numerous research studies have been conducted on risk management in China's PPP projects, the realization of risk management in China's construction industry especially in PPP projects with high risk exposure and complicated contract structure has hitherto not been well studied. This paper therefore attempted to examine the current use of risk management in China's PPP projects by an empirical survey. The results indicated that the use of risk management was inadequate; qualitative risk analysis methods were preferred to quantitative and semi-quantitative methods; risk management usage in the execution was found to be much higher than in the planning, conceptual or termination stage; interviewees were unfamiliar with most of the risk identification and assessment tools. All above could be partly due to the project nature, but more fundamentally due to the local industrial culture. The absence of risk management culture was found to be the dominant factor which limited the implementation of risk management in practice. Recommendations to alleviate the difficulties of risk management were thereafter provided in this paper.
\end{abstract}

Keywords: risk management, public-private partnership (PPP), China, infrastructure.

\section{Introduction}

\subsection{Public-Private Partnership in China}

Public-Private Partnership (PPP) modality was adopted to relieve the Chinese government's budgetary pressure in infrastructure construction and development, which was first introduced by local governments in 1980s. Later after 1996, several state-approved pilot Build-OperateTransfer (BOT) projects were awarded in order to introduce BOT on a larger scale (Chen 2009). Since then, the investment of private investors in infrastructure development had improved greatly. However, at the end of the decade to cope with the adverse influence of the financial crisis in Asia, the central government invested huge amounts of treasury bonds in infrastructure, and was determined to clean up the unregulated or illegal projects, which led to a termination of the first round of private investment (Shen et al. 2005).

Due to the fast economic growth in China and especially Beijing's success for the 2008 Olympic Games, public facilities were in high demand to cope with sustainable development in 2000s. The 4 trillion RMB stimulus plan as announced by the Chinese government in 2008 embarked on a massive infrastructure spending program to boost domestic demand (Chinese Government's Official Web Portal 2008). However, only 1.18 trillion came from the central government, and the rest would have to be topped up by the local government, and/or the private sector (NDRC 2009). Since most of the local governments were still subject to severe budgetary pressure, there was a heavy reliance on the private sector investment. PPP financing modality, with the ability of attracting foreign and private capital in the development of infrastructure, was therefore considered as an innovative tool for financing major infrastructure projects (Yuan et al. 2010; Cheung et al. 2010). As a result, the second boom of private investment in infrastructure development appeared (Ke et al. 2009).

Chinese government's active attitude has been seen to encourage and support private investors to participate in the infrastructure construction and public service supply. It is worth noting that "Several Opinions of the State Council on Encouraging and Guiding the Healthy Development of Private Investment" (so called "new 36 clauses") issued in May 2010 further widen the field and scope of private investment, which include railway, water conservancy projects, petroleum gas, telecommunication, land control, exploration and development of mineral resources, policy-related housing, medical industry, education, social welfare service, and as well as national defense science and technology industry (State Council 
2010). This new regulation would no doubt further promote the PPP implementations in near future.

\subsection{Risks in China's PPP projects}

However, the PPP application in China has evolved in an ad hoc and experimental manner and a mature Chinese PPP framework has not been established yet (Chen, Messner 2005). Therefore, only a few PPP projects in China could perform successfully (Chan et al. 2010a). In the authors' other publications, a desktop literature review and telephone interviews were conducted to collect actual data from PPP projects in China (Ke et al. 2010, 2011). As a part of the findings, some principal risks causing the failures of past cases were identified as shown in Table 1. Therefore, a proper management framework both theoretically and practically is important for PPP implementations due to the large project scale, long concession period, complexity and social sensitivity usually associated (Zhang 2005; Ke et al. 2010; Chan et al. 2010b).

\subsection{Literature review}

The subject of risk in PPP projects has become a very popular topic in recent years and is a much discussed issue amongst all levels of industry and government. Many researchers have offered detailed PPP risk registers and have assessed their relative importance, such as the United Nations Development Organization (UNIDO) (1996), Ozdoganm and Birgonul (2000), Zayed and Chang (2002), Hardcastle and Boothroyd (2003), Thomas et al. (2003), Ke et al. (2011), etc. Some of the frequently adopted risk management analysis techniques reported in international construction management journals included Monte Carlo simulation (Ye, Tiong 2000a), Analytical Hierarchy Process (AHP) (Hastak, Shaked 2000), and event tree and expedience probability as demonstrated by
Ezell et al. (2000). Research interests in risk management have continued to develop in recent years. Researchers have been adopting more complicated methods, such as fuzzy set theory (Thomas et al. 2006), game theory (Medda 2007), option pricing (Leung, Hui 2005), proactive contracting (Tieva, Junnonen 2009), minimum revenue guarantee and revenue cap agreements (Jun 2010), etc., instead of qualitative analyses that were used in earlier research work.

A comprehensive collection of literature regarding PPP projects in China has been carried out as well. For example, Zhang and Kumaraswamy (2001) provided an overview and analysis of the BOT-based approaches for infrastructure development in China. Ye and Tiong (2000b) looked at the relationship between government support and risk-return trade-off of the private partner in China's BOT power projects. The research team led by Dr Robert Tiong in Singapore contributed a lot of efforts on the risk and its management in China's BOT projects. These included the evaluation and management of political (Wang et al. 1999a, 2000a), foreign exchange and revenue risks (Wang et al. 2000b, c), risk management framework (Wang et al. 1999b), and also other studies on BOT projects in China (Zhang et al. 1998). Sachs et al. (2007) conducted a questionnaire survey to analyze the political risks and opportunities of PPP in China and other selected Asian countries. Ke et al. (2010) contributed to provide a preferred risk allocation scheme for PPP implementations in China. An impressive improvement of the Chinese governmental behaviors in PPP was seen in their results. Capitalizing on the Chinese government's increased PPP experience in the last two decades, they have made a lot of efforts to improve the investment environment, including moving towards the adoption of international contractual practices and working out an equitable risk-sharing scheme (Wang, Ke 2008; Chen, Doloi 2008).

Table 1. Principal risks encountered in past PPP projects of China

\begin{tabular}{l}
\hline Risk Case \\
\hline Change in law
\end{tabular}


While a few studies on the actual use of risk management in practice have been done, these primarily focused on developed construction industries such as Canada and the United States (Hegazy, Moselhi 1995), the United Kingdom (Akintoye, MacLeod 1997; Baker et al. 1999), Australia (Uher, Toakley 1999; Lyons, Skitmore 2004), etc. Although numerous researches have been conducted on the subject of risk management as well as PPP implementations in China, the realization of risk management in China's construction industry especially in PPP projects has hitherto not been well studied. Given the lesson that project risks were not properly managed in the past PPP projects in China (Ke et al. 2009), it is therefore necessary to examine the usage of risk management in PPP projects.

\subsection{Aim and objectives of this paper}

Because of the unique economic, environmental, cultural and political background in China, and the lack of advanced technology and management in the Chinese construction industry (Zou et al. 2007), this paper therefore aims to examine the current risk management practice in PPP projects in China. Other objectives of this study include to identify factors limiting the application of risk management theories, and to identify measures to improve the project risk management practice.

\section{Research methodology}

In light of the lessons learnt from past PPP projects, this study developed an empirical survey to collect feedback from practitioners on the following aspects of risk management in China's PPP projects. A series of structured interviews were conducted during February and April 2009 targeting managers who had hands-on experience in managing PPP projects in China.

The questionnaire of Lyons and Skitmore (2004) was selected as a basis for the structured interviews as presented in this paper with their prior permission. The usage of the following aspects of risk management in China's PPP projects would be examined:

- Risk tolerance of individuals and companies;

- Frequency of use of risk management techniques;

- Risk management usage in each of the project life cycle phases;

- The recording and use of historical risk data;

- Factors limiting the risk management practice.

The questionnaire adopted in the interviews comprised four sections. In the first section, background information was sought, such as business category, annual turnover, position in the company, years of experience. The second section investigated the respondents' risk tolerance, the risk management training respondents have had and the benefits obtained. The third section focused on the organizational experience with the application of risk management, including the company's risk tolerance, the frequency of use of risk management techniques, the recording and use of historical risk data and factors limiting the implementation of risk management. The last section looked for the opinions of respondents on the risk management practice in China's PPP projects and their expectations on the form and function of risk allocation and management tools. Answers for sections 2 and 3 were solicited on a 5-point Likert scale, i.e. $1=$ very low, $2=$ low, $3=$ moderate, $4=$ high, and $5=$ very high, while the questions in the last section were open questions to seek for the experience and understandings of experts in this topic.

By administering the questionnaire of Lyons and Skitmore (2004) again but in a different country would be of interest for comparison purposes in the future. The research scope in this paper is limited to risk management in PPP infrastructure projects instead of those in general construction projects as studied by Lyons and Skitmore (2004). Some characteristics distinguishing PPP projects from traditional construction projects include the huge investment, complicated contract structure, high risk, long concession period (usually covering the design, construction and operation), etc. Several questions were thus added to reflect the new context of PPP projects, i.e. roles of the organization in the PPP project, organizational use of risk allocation during contract negotiation, rationale of risk allocation in PPP contracts, form and functions of expected tools for risk allocation in PPP projects, etc.

A total of twenty managers from 20 different companies agreed to be interviewed after much persuasion and follow-up telephone calls. The twenty interviewees are senior or middle level managers in their companies. Ten out of twenty interviewees have more than 10 years working experience, eight with 5-10 years experience and only two with less than 5 years. Three companies have an annual turnover of less than 50 million RMB (US $\$ 1 \approx 6.78 \mathrm{RMB}$ ), three others have an annual turnover of 50-100 million RMB, and the remaining fourteen companies have an annual turnover of more than 100 million RMB. All these respondents have been involved in one or more PPP projects in China. This confirms that respondents participating in this survey have rich experience in PPP financing and therefore their views would be useful for further analysis. The data of interview survey were presented in Table 2 .

Table 2. Survey results

\begin{tabular}{l|c|c}
\hline \multicolumn{1}{c|}{ Items } & Freq./Mean & SD \\
\hline Personal risk tolerance & & \\
\hline Averse & 3 & - \\
\hline Neutral & 12 & - \\
\hline Taker & 5 & - \\
\hline Personal knowledge of risk management & 2.90 & 0.718 \\
\hline Level of training in risk management & 1.89 & 0.737 \\
\hline Organizational risk tolerance & & \\
\hline Averse & 5 & - \\
\hline Neutral & 14 & - \\
\hline Taker & 1 & - \\
\hline $\begin{array}{l}\text { Organizational use of risk management } \\
\text { in PPP projects }\end{array}$ & 2.45 & 0.826 \\
\hline $\begin{array}{l}\text { Organizational use of risk allocation in } \\
\text { contract negotiation }\end{array}$ & 2.70 & 0.979 \\
\hline $\begin{array}{l}\text { Rationality of risk allocation in PPP } \\
\text { contracts }\end{array}$ & 2.88 & 0.806 \\
\hline
\end{tabular}


Continue of Table 2

\begin{tabular}{|c|c|c|}
\hline Items & Freq./Mean & SD \\
\hline \multicolumn{3}{|l|}{ Frequency of use of computers } \\
\hline Cost accounting & 4.59 & 0.618 \\
\hline Databases & 3.00 & 1.225 \\
\hline Risk management & 2.24 & 0.970 \\
\hline Scheduling & 3.76 & 0.970 \\
\hline \multicolumn{3}{|l|}{ Risk analysis method usage frequency } \\
\hline Qualitative & 3.71 & 1.047 \\
\hline Semi-quantitative & 2.47 & 1.179 \\
\hline Quantitative & 2.53 & 1.179 \\
\hline \multicolumn{3}{|l|}{$\begin{array}{l}\text { Risk management element usage } \\
\text { frequency }\end{array}$} \\
\hline Risk management planning & 2.35 & 1.115 \\
\hline Risk identification & 3.35 & 1.057 \\
\hline Risk assessment & 3.24 & 1.147 \\
\hline Risk allocation & 2.76 & 1.147 \\
\hline Risk response & 3.07 & 1.100 \\
\hline Risk documentation & 2.35 & 1.169 \\
\hline \multicolumn{3}{|l|}{$\begin{array}{l}\text { Risk management usage in project life } \\
\text { cycle phases }\end{array}$} \\
\hline Conceptual & 2.88 & 1.364 \\
\hline Planning & 3.06 & 1.029 \\
\hline Execution & 3.76 & 0.831 \\
\hline Termination & 2.35 & 1.169 \\
\hline \multicolumn{3}{|l|}{ Risk identification tool usage } \\
\hline Documentation Reviews & 3.35 & 1.169 \\
\hline Brainstorming & 2.35 & 1.057 \\
\hline Delphi technique & 1.53 & 0.717 \\
\hline Interviewing & 2.35 & 1.222 \\
\hline SWOT analysis & 2.94 & 1.197 \\
\hline Checklist analysis & 2.06 & 1.088 \\
\hline Similar cases comparison & 3.00 & 1.173 \\
\hline Cause-and-effect/Influence diagrams & 2.18 & 1.015 \\
\hline System or process flow charts & 2.29 & 1.105 \\
\hline Scenario assumptions Analysis & 1.82 & 1.131 \\
\hline $\begin{array}{l}\text { Frequency of recording risks in a risk } \\
\text { management database }\end{array}$ & 2.31 & 1.195 \\
\hline Historical risk data usage frequency & 3.00 & 1.265 \\
\hline \multicolumn{3}{|l|}{ Risk analysis technique usage } \\
\hline Sensitivity analysis & 3.00 & 1.225 \\
\hline Expected monetary value & 2.19 & 1.167 \\
\hline Decision tree analysis & 2.53 & 0.943 \\
\hline Monte Carlo simulation & 1.59 & 0.618 \\
\hline Risk probability and impact matrix & 2.12 & 0.928 \\
\hline Risk adjusted discount rate & 1.71 & 0.849 \\
\hline Risk premium & 1.71 & 0.849 \\
\hline Risk categorization & 2.94 & 1.345 \\
\hline Risk urgency assessment & 3.00 & 1.118 \\
\hline Intuition/judgment/experience & 3.65 & 0.862 \\
\hline \multicolumn{3}{|l|}{ Risk response technique usage } \\
\hline Contingencies & 3.35 & 1.367 \\
\hline Contractual transfer & 3.18 & 1.015 \\
\hline Insurance & 2.29 & 1.160 \\
\hline \multicolumn{3}{|l|}{ Contingency percentage usage } \\
\hline $0-5 \%$ & 4 & - \\
\hline $6-10 \%$ & 9 & - \\
\hline $11-15 \%$ & 0 & - \\
\hline $16-20 \%$ & 1 & - \\
\hline$>20 \%$ & 1 & - \\
\hline
\end{tabular}

End of Table 2

\begin{tabular}{l|c|c}
\hline \multicolumn{1}{c|}{ Items } & Freq./Mean & SD \\
\hline $\begin{array}{l}\text { Factors preventing implementation of } \\
\text { risk management }\end{array}$ & & \\
\hline Cost effectiveness & 3.11 & 1.183 \\
\hline Lack of time & 3.00 & 1.085 \\
\hline Lack of information & 3.06 & 1.259 \\
\hline Difficulties in seeing the benefits & 2.89 & 0.900 \\
\hline Human/organizational resistance & 3.35 & 1.348 \\
\hline $\begin{array}{l}\text { Lack of accepted industry } \\
\text { tools/techniques for analysis }\end{array}$ & 3.39 & 1.335 \\
\hline $\begin{array}{l}\text { Lack of experts familiar with the } \\
\text { tools/techniques }\end{array}$ & 3.72 & 1.406 \\
\hline
\end{tabular}

One limitation of this study is the small sample size. Therefore, the findings are not appropriate for comparative statistical analysis of responses from different types of organizations (i.e. contractors, consultants, owners and developers). It is possible that Chinese and Australian managers might respond differently to questions of this nature due to the cultural differences (e.g. respondents may be too optimistic or modest to give an imprecise score on the self-evaluation questions by the linguistic scale). The comparative analysis between the survey responses in this paper and Lyons and Skitmore (2004) may be questionable to some extent. The cultural differences would therefore be considered when analyzing the differences of the survey results.

\section{Discussion and management implications}

\subsection{Individual risk tolerance and training}

The majority of interviewees considered themselves as risk neutral. Interviewees considered their individual experience/knowledge of risk management to be low to moderate with a score of 2.90 as shown in Fig. 1 and Table 2, which is different from the finding of "moderate to high" in the Australian survey by Lyons and Skitmore (2004). This observation may reflect that managers in China's PPP projects have less experience in risk management than those in the Australian construction industry. It is also possible that due to the cultural differences Chinese managers may be modest to undervalue their experience/knowledge level.

Moreover, the level of training in risk analysis and management techniques was found to be very low with a score of 1.89 , which clearly indicated that there was a lack of training in risk analysis and management techniques by most of the interviewees. The maximum score by the interviewees regarding the level of their training in risk management was 3 (moderate), which yet again reinforces the lack of risk management culture in

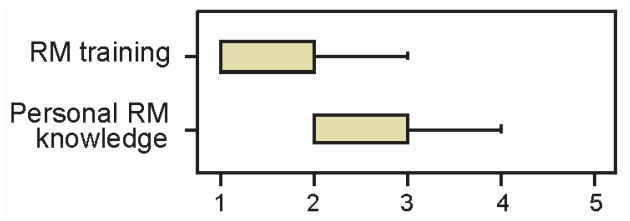

Fig. 1. Individual risk management knowledge and training 
China's PPP projects. Ten respondents have indicated the most beneficial risk management training that they had received. These responses comprised three long-term course studies and seven seminars, which were all about project management and strategic management.

\subsection{Organizational use of risk management}

Compared to the individual risk tolerance, more respondents considered their companies as risk averse or neutral. In other words, organizations are more prudent towards risk taking compared to individuals, which could explain the following arguments to some extent. When investing a PPP project, the companies undertook risk management on a low frequency of 2.45 and risk allocation during the contract negotiation on a low to moderate frequency of 2.70. The rationale of risk allocation in PPP contracts were considered as low to moderate with a score of 2.88 . However, according to Fig. 2, a lower agreement of the respondents on the risk allocation usage in contract negotiation could be observed. It means that although the mean value was smaller than 3 , there were still some companies who already took into account risk allocation in the contract negotiation. This is a positive sign because risk allocation, the definition and division of responsibility associated with a possible future loss or gain, seeks to assign responsibility for a wide variety of hypothetical circumstances, which is commonly defined through the contractual documents as a part of a risk management strategy (Lam et al. 2007).

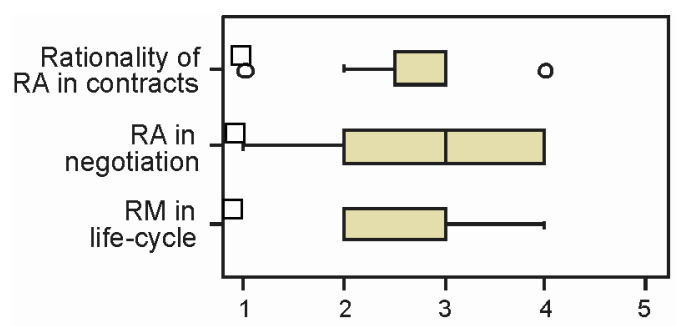

Fig. 2. Organizational use of risk allocation \& management

\subsection{Risk management usage in practice}

For the information technology, the use of computers was found to be much lower for risk management than for cost accounting, scheduling or databases (Fig. 3). This is also in line with the findings of Lyons and Skitmore (2004) in Australia. However, computer based risk management programs were not as popular as time management programs at the time of their survey in 2002. It is

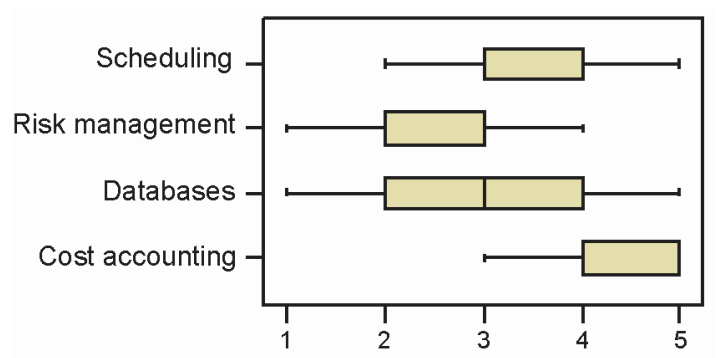

Fig. 3. Computer usage in PPP projects hence understandable that computers were not frequently used in risk management. But the absence of computer application in current management in PPP projects in China now may reflect the lack of the risk management culture of these companies, as commercial risk management software has experienced a great development in recent years (Dikmen et al. 2004).

The usage frequency was greater for qualitative than for semi-quantitative and quantitative methods (Fig. 4). Risk identification, assessment and response were the most often used risk management elements than risk allocation, management planning and documentation (Fig. 5). In addition as presented in Fig. 6, risk management usage in the execution stage (score 3.76) was found to be much higher than in the other three stages of the project life cycle, i.e. planning (score 3.06), conceptual (score 2.88) or termination (score 2.35). The late start of risk management was identified in China's PPP projects, which may create rushing and the missing out of vital details and hence reduce the efficacy of risk assessment and response (Chinyio, Fergusson 2003). These observations again reinforce the assertion that investors in PPP projects in China are in lack of risk management planning and skills. This also has caused the failure of several past PPP projects in China (Wang, Ke 2008) and hence why it was considered as an obstacle to successful implementation of PPP projects in China (Chan et al. 2010a).

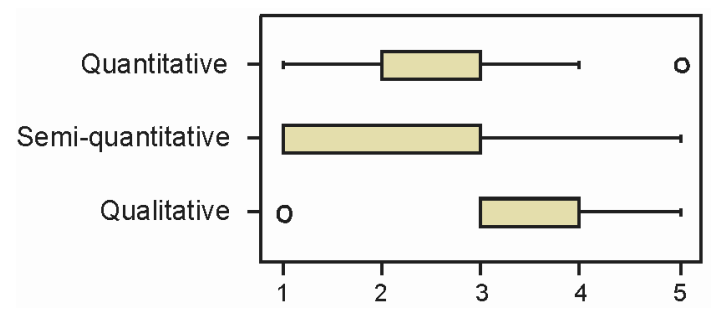

Fig. 4. Risk analysis method usage in PPP projects

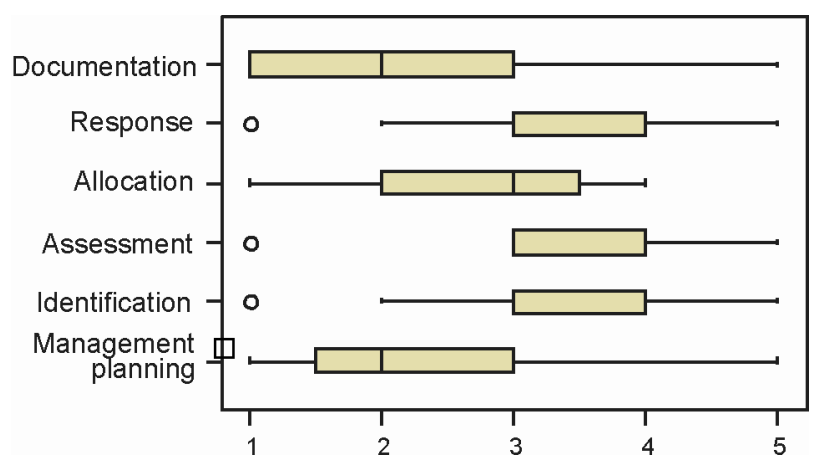

Fig. 5. Risk management element usage in PPP projects

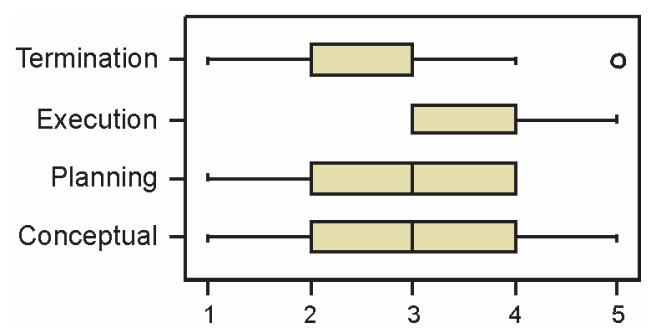

Fig. 6. Risk management element usage in PPP projects 
Table 2 and Fig. 7 indicated that most of the risk identification tools were seldom used in past PPP projects. Seven out of ten tools in the list received a mean score lower than 2.35. Documentation reviews, similar cases comparison and SWOT analysis were the most frequently used tools to identify risks. However, the usage frequency of these three tools was only a little greater than moderate. Moreover, the use of risk management databases to record project risks was found to be low to moderate (score 2.31), along with the moderate usage of such risk data on other projects (score 3.00). This may be because the use of computers for risk management was much lower than for other tasks as described above, and interviewees had to record risks in other ways, e.g. by the use of hand written risk registers, which obviously reduce the possibility and willingness of the companies for risk documentation. This situation was exacerbated when PPP practice was relatively new as there was often no experience or track record to follow.

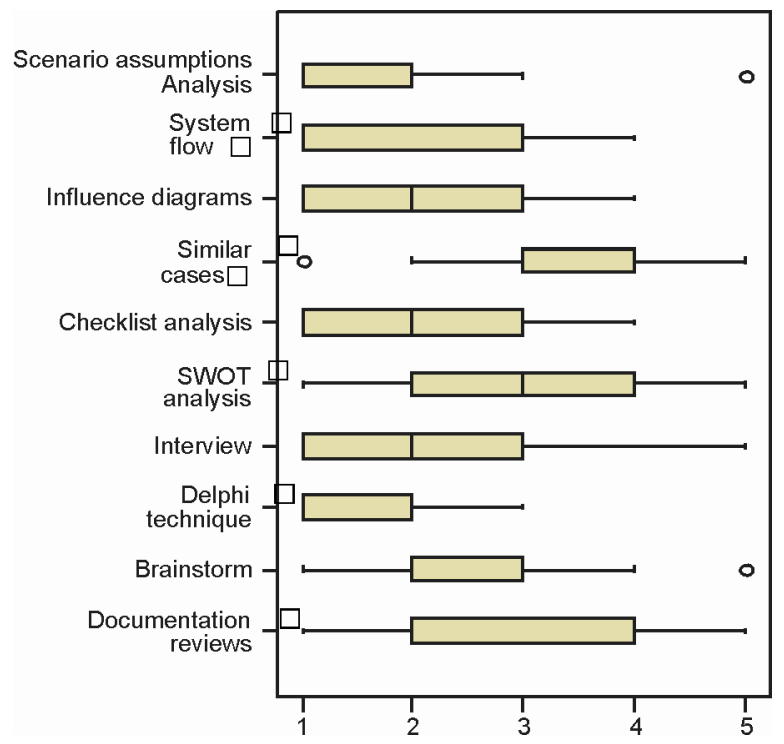

Fig. 7. Risk identification tool usage in PPP projects

Among the ten risk analysis techniques, intuition, judgment and experience was the most frequently used tools with a highest score of 3.65. The other frequently used tools included risk urgency assessment, sensitivity analysis and risk categorization. Sensitivity analysis was the only quantitative technique frequently used, which again reinforces that qualitative methods of risk assessment were used more frequently than quantitative and semi-qualitative methods. The interviewees scored very low to the remaining quantitative tools such as expected monetary value, decision tree analysis, Monte Carlo simulation, risk probability and impact matrix, risk adjusted discount rate and risk premium. It could be also seen that the maximum scores of many risk analysis techniques were only 3 or 4 from Fig. 8, which means that not even one company had been active to adopt these techniques in any project. One of the reasons may be due to the fact that risks were assessed on the basis of subjective judgment and individual experience because of the dearth of historical data documented.

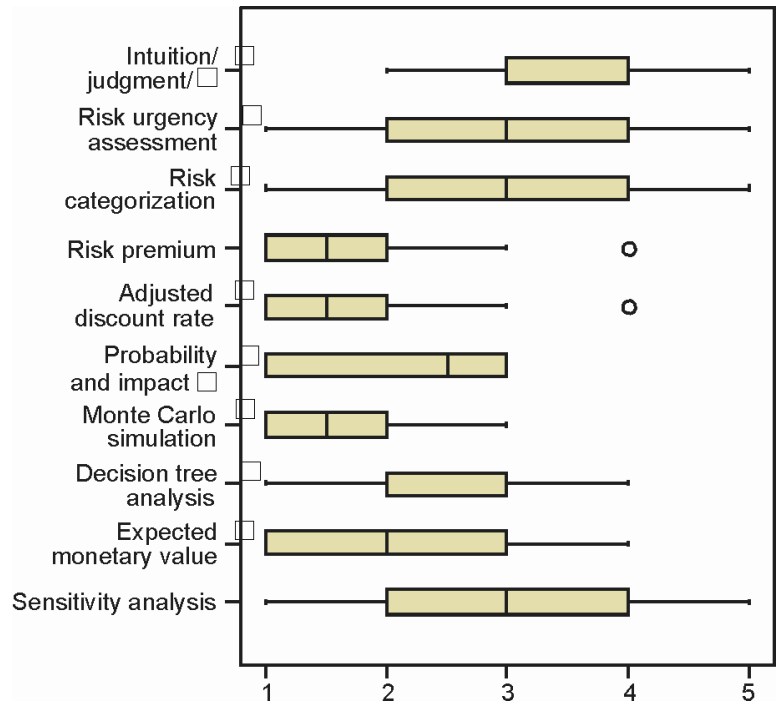

Fig. 8. Risk analysis technique usage in PPP projects

Among the risk response techniques, it was found in Fig. 9 that contingencies was the most frequently used one (score 3.35) than contractual transfer (score 3.18) and insurance (score 2.29). The most often adopted percentage range for the contingencies was $6-10 \%$. However, when asking how to determine this percentage, interviewees all considered it as a common practice without precise calculations. It could be remarked that the efficacy of risk assessments cannot be ascertained in view of the foregoing issue, as it is easy to say a $10 \%$ for contingencies while in reality it may be more than $10 \%$. In this case, even though projects are completed or are running successfully, the client may not get the optimal value for money. It is noted that insurance was seldom used in China's PPP projects. This may be due to the fact that PPP financing model is a relatively new financial modality and is unfamiliar to the insurers. Although PPP projects via BOT model were first seen in 1980s, it is still in an immature and developing stage. For example, there is no official PPP law in place yet and there has been a big public accountability concern to the private investors. Therefore, insurers chose not to present their support in these projects.

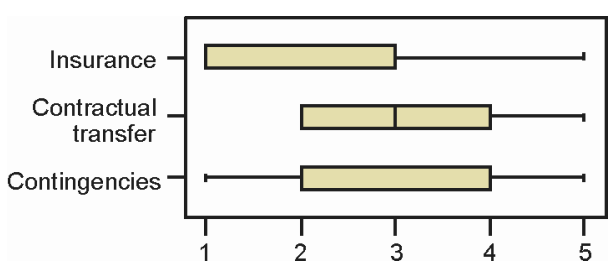

Fig. 9. Risk response technique usage in PPP projects

\subsection{Factors limiting the implementation of risk management}

The survey results as presented in Fig. 10 and Table 2 showed that the most dominant factor was "Lack of experts familiar with the tools/techniques", which had the highest mean score of 3.72. Factors "Lack of accepted industry tools/techniques for analysis" and "Human/organizational resistance" were ranked 2 nd and 3 rd. 
Referring back to the individual knowledge and experience of risk management of the interviewees described in section 3.1, it was found that most senior and middle level managers in the companies admitted their individual experience and knowledge of risk management as below moderate. It is hence understandable why "Lack of experts familiar with the tools/techniques" and "Human/organizational resistance" have been considered as critical factors preventing the implementation of risk management in practice. However, because the interview results showed that the interviewees did not seem to be familiar with some common risk identification or assessment tools listed in the questionnaire, the authors would argue that the factor "Lack of accepted industry tools/techniques for analysis" may not be a critical reason.

All in all, it could be concluded that these internal factors (such as lack of experts familiar with the tools/techniques and human/organizational resistance) inside the companies were more important than the external ones, such as lack of time, resources, information, etc. It can be thereafter construed that the dominant reason which limits the implementation of risk management was the absence of risk management culture in these companies.

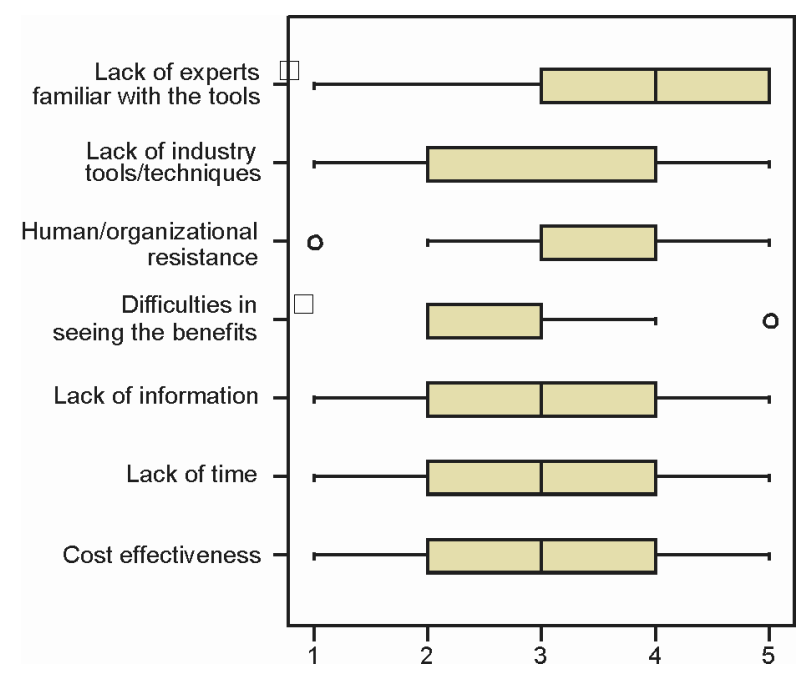

Fig. 10. Factors preventing risk management practices

\section{Measures alleviating the difficulties of risk management}

In light of the problems discussed above, solutions were also sought on how to alleviate the difficulties of risk management in practice. First of all, the training of risk analysis and management is considered as one of the notable preferred solutions, because it would theoretically and practically facilitate a better understanding of risks for the organizations and their employees. Given that the risks pertaining to the public sectors' behaviors were always regarded as the principal ones affecting the success of PPP projects in China (Sachs et al. 2007), the need for motivating them to be more alert to the potential risks is becoming more urgent.
The establishment of standard risk management process in the company is another efficient measure. The process may include how to use a PPP database, when to start the risk analysis, who to take the responsibilities, and what structured approach to be adopted. After running PPP projects for a while, participants would be able to develop more reliable information on similar procurement and also understand better what may constitute a risk and how to manage it. It is therefore beneficial to set up a PPP database to support risk analysis and management. In a PPP project, which is obviously different from traditional construction projects, the laxity of risk review and late start of risk management of the private companies would become potential risks during the concession period and may cause huge loss. More detailed risk management planning would surely help the participants identify a myriad of risks that could easily go unnoticed (Chinyio, Fergusson 2003). The interview survey showed that the interviewees were not totally familiar with some common risk identification and assessment tools. Further training to executives on risk analysis as recommended above is then essential. Moreover, adopting a more structured approach to risk assessment might be effective, since it would introduce transparency to the process (Chinyio, Fergusson 2003) and make it easier for the risk documentation process.

\section{Conclusions}

Although numerous researches have been carried out on the subject of risk management in PPP projects, project risks were still not well managed in many past PPP projects in China. This observation inspired the authors that there might be a gap in between the risk management theory study and the realization of these theories via various tools in the management in China's PPP projects. This paper thus attempts to examine the current PPP risk management practice in China. A series of interviews were used to canvass the opinions of managers who have hands-on experience in PPP projects in China from February to April 2009. As a brief summary, the results from the survey included that:

- The absence of risk management culture is the dominant factor that limits the implementation of risk management in practice. It stems from the result that internal factors like the lack of experts who are familiar with the risk management tools and human/organizational resistance were considered as more critical than those external factors;

- In particular, these senior and middle level managers considered their personal experience and knowledge of risk management to be below moderate; and the level of training in risk analysis and management was also found to be very low;

- The companies undertake risk management on a low frequency especially risk allocation during the contract negotiation when investing a PPP project. The rationale for risk allocation in PPP contracts was considered as low to moderate;

- The usage frequency was greater for qualitative methods of risk analysis than for quantitative and 
semi-qualitative methods. Documentation reviews, similar cases comparison and SWOT analysis were the most frequently used tools to identify risks. Intuition, judgment and experience were the most frequently used tools to assess risks;

- Risk identification, assessment and response were the most often used risk management elements than risk allocation, management planning and documentation. In addition, risk management usage in the execution phase was found to be much higher than in the other three stages of the project life cycle, i.e. planning, conceptual or termination;

- Among the risk response techniques, it was found that provision for contingencies was the most preferred technique than contractual transfer and insurance. The most often adopted percentage range for the contingencies was $6-10 \%$.

All the findings above clearly prove that there is apparently a significant gap in between the theory study and the practice of risk management in China's PPP projects. Recommendations to alleviate the difficulties of risk management were also provided in this paper, for example, training of risk analysis and management especially for the public sectors. The establishment of standard risk management process in the company is another efficient measure, which may include how to use a PPP database, when to start the risk analysis, who to take the responsibilities, and what structured approach to be adopted.

\section{Acknowledgements}

The work described in this paper was fully supported by a joint grant from the National Natural Science Foundation of China (Project No. 70731160634) and the Research Grants Council of the Hong Kong Special Administrative Region, China (RGC Project N_PolyU514/07). Sincere thanks goes to Dr. Terry Lyons and Prof. Martin Skitmore for permitting the research team to adapt their survey questionnaire template. Special gratitude is also extended to those industrial practitioners, who have kindly participated in the interviews reported in this paper from February to April 2009.

\section{References}

Akintoye, A. S.; MacLeod, M. J. 1997. Risk analysis and management in construction, International Journal of Project Management 15(1): 31-38.

http://dx.doi.org/10.1016/S0263-7863(96)00035-X

Baker, S.; Ponniah, D.; Smith, S. 1999. Risk response techniques employed currently for major projects, Construction Management and Economics 17(2): 205-213. http://dx.doi.org/10.1080/014461999371709

Chan, A. P. C.; Lam, P. T. I.; Chan, D. W. M.; Cheung, E.; Ke, Y. 2010a. Potential obstacles to successful implementation of Public-Private Partnerships in Beijing and the Hong Kong Special Administrative Region, Journal of Management in Engineering ASCE 26(1): 30-40. http://dx.doi.org/10.1061/(ASCE)0742-597X(2010)26: $1(30)$
Chan, A. P. C.; Lam, P. T. I.; Chan, D. W. M.; Cheung, E.; Ke, Y. 2010b. Critical success factors for PPPs in infrastructure developments: Chinese perspective, Journal of Construction Engineering and Management ASCE 136(5): 484-494. http://dx.doi.org/10.1061/(ASCE)CO. 1943-7862.0000152

Chen, C.; Messner, J. I. 2005. An investigation of Chinese BOT projects in water supply: a comparative perspective, Construction Management and Economics 23(9): 913-925. http://dx.doi.org/10.1080/01446190500184121

Chen, C.; Doloi, H. 2008. BOT application in China: Driving and impeding factors, International Journal of Project Management 26(4): 388-398.

http://dx.doi.org/10.1016/j.ijproman.2007.07.002

Chen, C. 2009. Can the pilot BOT Project provide a template for future projects? A case study of the Chengdu No. 6 Water Plant B Project, International Journal of Project Management 27(6): 573-583.

http://dx.doi.org/10.1016/j.ijproman.2008.10.006

Cheung, E.; Chan, A. P. C.; Kajewski, S. 2010. The public sector's perspective on procuring public works projects comparing the views of practitioners in Hong Kong and Australia, Journal of Civil Engineering and Management 16(1): 19-32. http://dx.doi.org/10.3846/jcem.2010.02

Chinese Government's Official Web Portal. 2008. China's 4 Trillion Yuan Stimulus to Boost Economy, Domestic Demand [cited 28 May 2011]. Available from Internet: $<$ http://www.gov.cn/english/2008-11/09/content_ 1143763. htm $>$.

Chinyio, E.; Fergusson, A. 2003. A construction perspective on risk management in public-private partnership, in A. Akintoye, M. Beck, C. Hardcastle. Public-Private Partnerships: Managing Risks and Opportunities. Oxford: Blackwell Science Ltd., 95-126.

Dikmen, I.; Birgonul, M. T.; Arikan, A. E. 2004. A critical review of risk management support tools, in Proc. of the 20th Annual Association of Researchers in Construction Management (ARCOM) Conference, 1-3 September, 2004, Heriot-Watt University, Edinburgh, UK, 11451154 .

Ezell, B. C.; Farr, J. V.; Wiese, I. 2000. Infrastructure risk analysis of municipal water distribution system, Journal of Infrastructure Systems ASCE 6(3): 118-122. http://dx.doi.org/10.1061/(ASCE)1076-0342(2000)6: $3(118)$

Hardcastle, C.; Boothroyd, K. 2003. Risks overview in publicprivate partnership, in A. Akintoye, M. Beck, C. Hardcastle. Public-Private Partnerships: Managing Risks and Opportunities. Oxford: Blackwell Science Ltd., 31-57.

Hastak, M.; Shaked, A. 2000. ICRAM-1: model for international construction risk assessment, Journal of Management in Engineering ASCE 16(1): 59-69. http://dx.doi.org/10.1061/(ASCE)0742-597X(2000)16: $1(59)$

Hegazy, T.; Moselhi, O. 1995. Elements of cost estimation: A survey in Canada and the United States, Cost Engineering 37(5): 27-33.

Jun, J. 2010. Appraisal of combined agreements in BOT project finance: Focused on minimum revenue guarantee and revenue cap agreements, International Journal of Strategic Property Management 14(2): 139-155. http://dx.doi.org/10.3846/ijspm.2010.11

Ke, Y. J.; Wang, S. Q.; Chan, A. P. C. 2009. Public-Private Partnerships in China's infrastructure development: lessons learnt, in Proc. of the Changing roles: new roles, 
new challenges, 5-9 October, 2009, Noordwijk ann Zee, Netherlands, 177-188.

Ke, Y.; Wang, S. Q.; Chan, A. P. C.; Lam, P. T. I. 2010. Preferred risk allocation in China's Public-Private Partnership (PPP) projects, International Journal of Project Management 28(5): 482-492.

http://dx.doi.org/10.1016/j.ijproman.2009.08.007

Ke, Y.; Wang, S. Q.; Chan, A. P. C.; Cheung, E. 2011. Understanding the risks in China's PPP projects: Ranking of their probability and consequence, Engineering, Construction and Architectural Management 18(5): 481-496. http://dx.doi.org/10.1108/09699981111165176

Lam, K. C.; Wang, D.; Lee, P. T. K.; Tsang, Y. T. 2007. Modelling risk allocation decision in construction contracts, International Journal of Project Management 25(5): 485493.

Leung, B. Y. P.; Hui, E. C. M. 2005. Evaluation approach on Public-Private Partnership (PPP) urban redevelopments, International Journal of Strategic Property Management 9(1): 1-16.

Lyons, T.; Skitmore, M. 2004. Project risk management in the Queensland engineering construction industry: a survey, International Journal of Project Management 22(1): 5161. http://dx.doi.org/10.1016/S0263-7863(03)00005-X

Medda, F. 2007. A game theory approach for the allocation of risks in transport public private partnerships, International Journal of Project Management 25(3): 213-218. http://dx.doi.org/10.1016/j.ijproman.2006.06.003

National Development and Reform Commission (NDRC). 2009. More information about 4 trillion RMB stimulus plan (in Chinese) [cited 28 May 2011]. Available from Internet: $\quad<$ http://www.ndrc.gov.cn/xwfb/t20090309 265095.htm>.

Ozdoganm, I. D.; Birgonul, M. T. 2000. A decision support framework for project sponsors in the planning stage of Build-Operate-Transfer (BOT) projects, Construction Management and Economics 18(3): 343-353. http://dx.doi.org/10.1080/014461900370708

Sachs, T.; Tiong, R. L. K.; Wang, S. Q. 2007. Analysis of political risks and opportunities in Public Private Partnerships (PPP) in China and selected Asian Countries - survey results, Chinese Management Studies 1(2): 126-148. http://dx.doi.org/10.1108/17506140710758026

Shen, J. Y.; Wang, S. Q.; Qiang, M. S. 2005. Political risks and sovereign risks in Chinese BOT/PPP projects: a case study (in Chinese), Chinese Businessman Investment and Finance 2005(1): 50-55.

State Council. 2010. Several Opinions of the State Council on Encouraging and Guiding the Healthy Development of Private Investment. China, May 7, 2010.

Thomas, A. V.; Kalidindi, S. N.; Ananthanarayanan, K. 2003. Risk perception analysis of BOT road project participants in India, Construction Management and Economics 21(4): 393-407. http://dx.doi.org/10.1080/0144619032000064127

Thomas, A. V.; Kalidindi, S. N.; Ganesh, L. S. 2006. Modelling and assessment of critical risks in BOT road projects, Construction Management and Economics 24(4): 407424. http://dx.doi.org/10.1080/01446190500435275

Tieva, A.; Junnonen, J.-M. 2009. Proactive contracting in Finnish PPP projects, International Journal of Strategic Property Management 13(3): 219-228. http://dx.doi.org/10.3846/1648-715X.2009.13.219-228
UNIDO. 1996. Guidelines for Infrastructure Development through BOT Projects. United Nations Development Organization, Vienna. $308 \mathrm{p}$.

Uher, T. E.; Toakley, A. R. 1999. Risk management in the conceptual phase of a project, International Journal of Project Management 17(3): 161-169. http://dx.doi.org/10.1016/S0263-7863(98)00024-6

Wang, S. Q.; Tiong, R. L. K.; Ting, S. K.; Ashley, D. 1999a. Political risks: analysis of key contract clauses in China's BOT project, Journal of Construction Engineering and Management ASCE 125(3): 190-197.

http://dx.doi.org/10.1061/(ASCE)0733-9364(1999)125: $3(190)$

Wang, S. Q.; Tiong, R. L. K.; Ting, S. K.; Ashley, D. 1999b. Risk management framework for BOT power projects in China, The Journal of Structured Finance 4(4): 56-67. http://dx.doi.org/10.3905/jsf.1999.320194

Wang, S. Q.; Tiong, R. L. K.; Ting, S. K.; Ashley, D. 2000a. Evaluation and management of political risks in China's BOT projects, Journal of Construction Engineering and Management ASCE 126(3): 242-250. http://dx.doi.org/10.1061/(ASCE)0733-9364(2000)126: $3(242)$

Wang, S. Q.; Tiong, R. L. K.; Ting, S. K.; Ashley, D. 2000 b. Evaluation and management of foreign exchange and revenue risks in China's BOT projects, Construction Management and Economics 18(2): 197-207. http://dx.doi.org/10.1080/014461900370825

Wang, S. Q.; Tiong, R. L. K.; Ting, S. K.; Ashley, D. 2000c. Foreign exchange and revenue risks: analysis of key contract clauses in China's BOT project, Construction Management and Economics 18(3): 311-320. http://dx.doi.org/10.1080/014461900370672

Wang, S. Q.; Ke, Y. J. 2008. Risk management of infrastructure projects in China with case study of the National Stadium, in Proc. of the Inaugural Conference on Construction Law and Economics Circle in Asia and Pacific, 27-28 October, 2008, Kyoto University, Kyoto, Japan, 101-114.

Ye, S. D.; Tiong, R. L. K. 2000a. NPV-AT-RISK method in infrastructure project investment evaluation, Journal of Construction Engineering and Management ASCE 126(3): 227-233. http://dx.doi.org/10.1061/(ASCE)07339364(2000)126:3(227)

Ye, S. D.; Tiong, R. L. K. 2000b. Government support and riskreturn trade-off in China's BOT power projects, Engineering, Construction and Architectural Management 7(4): 412-422. http://dx.doi.org/10.1046/j.1365-232x.2000. 00175.x

Yuan, J. F.; Skibniewski, M. J.; Li, Q.; Shan, J. 2010. The driving factors of China's public-private partnership projects in metropolitian transportation systems: Public sector's viewpoint, Journal of Civil Engineering and Management 16(1): 5-18. http://dx.doi.org/10.3846/jcem.2010.01

Zayed, T. M.; Chang, L.-M. 2002. Prototype model for BuildOperate-Transfer risk assessment, Journal of Management in Engineering ASCE 18(1): 7-16.

http://dx.doi.org/10.1061/(ASCE)0742-597X(2002)18:1(7)

Zhang, W. R.; Wang, S. Q.; Tiong, R. L. K.; Ting, S. K.; Ashley, D. 1998. Risk management of Shanghai's privatelyfinanced Yan'an Donglu Tunnels, Engineering, Construction and Architectural Management 5(4): 399-409. http://dx.doi.org/10.1108/eb021092 
Zhang, X.-Q. 2005. Critical success factors for Public-Private Partnerships in infrastructure development, Journal of Construction Engineering and Management ASCE 131(1): 3-14.

http://dx.doi.org/10.1061/(ASCE)0733-9364(2005)131:1(3)

Zhang, X.-Q.; Kumaraswamy, M. M. 2001. BOT-based approaches to infrastructure development in China, Journal of Infrastructure Systems ASCE 7(1): 18-25.

http://dx.doi.org/10.1061/(ASCE)1076-0342(2001)7:

$1(18)$

Yongjian KE. Currently a research fellow in the Department of Building at National University of Singapore, Singapore. This paper is based on a part of his $\mathrm{PhD}$ thesis defended at Department of Construction Management, Tsinghua University, China. His research interests include project management (especially risk management) in public construction projects and Public-Private Partnership projects.

ShouQing WANG. Professor in the Department of Construction Management, and Deputy Director of the Institute of International Engineering Project Management, Tsinghua University, China. He is also the Chairman of China National Collaboration Network for M.Eng. (PM) Education. His research interests include project/risk management in Public-Private Partnership projects.

Albert P. C. CHAN. Professor in the Department of Building and Real Estate, The Hong Kong Polytechnic University, Hong Kong, China. He is also an Associate Dean of the Faculty of Construction and Environment. His research interests include project management \& project success, project finance \& Public-Private Partnerships, construction procurement \& relationship contracting, construction industry development, construction safety. 